\title{
Study on establishment of ecological water system in Lanzhou
}

\author{
Wang Enyong ${ }^{1, a^{*}}$, Qian Guoquan ${ }^{2, b *}$, Gao Tianpeng ${ }^{3, c}$, Cui Jianbo ${ }^{4, d}$, \\ Cao Xiuge ${ }^{5, e}$ \\ ${ }^{1}$ Lanzhou City University, Lanzhou City, Gansu Province, China,730070 \\ *2 Lanzhou City University, Lanzhou City, Gansu Province, China,730070 \\ ${ }^{3}$ Lanzhou City University, Lanzhou City, Gansu Province, China,730070 \\ ${ }^{4}$ Lanzhou City University, Lanzhou City, Gansu Province,China,730070 \\ ${ }^{5}$ Lanzhou City University, Lanzhou City, Gansu Province,China,730070 \\ a595262628@qq.com, b599037529@qq.com, '549297696@qq.com
}

\begin{abstract}
Keywords: ecological environment, water diverting, ecological water system in Lanzhou Abstract. This paper has analyzed status quo of drought in Lanzhou and the reason why not make full usage of the Yellow River to improve the local environment. It also includes present status of wetland, wild plants, plant, aquatic plants and wild animals in Lanzhou. Research and put forward the scheme of using altitude difference to water diversion and establish an ecological water supply system on the two mountains and the city. The completed detailed study report has been adopted by Lanzhou city government basically, and has won the provincial social science achievement award certificate.
\end{abstract}

\section{Introduction}

This paper provides a general introduction of a systematic and scientific ecological water project in Lanzhou. As we all know the capital of Gansu province Lanzhou suffers severe water problem such as drought and shortage of city water because of its special geographical position and special climate. Besides, due to serious air and water pollution problem in Lanzhou the quality of Lanzhou's city water is another problem need to be solved. In order to improve the ecological environment of Lanzhou and the quality of city water, this paper suggests diverting high-quality water from Lijiaxia reservoir and building a structured ecological water system in Lanzhou. It is noted that the project has been invested by the government of Lanzhou and has won the provincial social science achievement award certificate.

\section{Arid environment and water resources in Lanzhou}

Lanzhou city is located in the middle of the northwest arid region of China, the capital of the Gansu province. The quantity of local water resources is only 30.75 billion $\mathrm{m}^{3}$. The quantity is less than half of the national average and 1/8 of the world average. There is no obvious difference in Gansu. Therefore, Gansu province is one of the poorest provinces in water resources in China. The urban average quantity of rainfall is only around $360 \mathrm{~mm}$, while the urban average evaporation quantity is about $17000 \mathrm{~mm}$, which is about 3 times of the quantity of rainfall. Although the Yellow River flows through the city, it is hardly used, in addition to being used to generate electricity and also recharge ground water to a small extent naturally. Affected by the drought, the distribution of precipitation around Lanzhou city is very uneven, as showed in the Figure 1. Not only the quantity but also the quality of the groundwater and the rainfall in Lanzhou is relative poor. The main surface water resource in Lanzhou is from east section of Lenglong ridge of Qilian Mountains and southern Xinglong Mountain. Runoff depths of the surface water are100 $\mathrm{mm}$ from the Lenglong ridge and $70 \mathrm{~mm}$ from the Xinglong Mountain. The drainage areas of these two mountains in the Gansu province are $1300 \mathrm{~km}^{2}$ and 1300 $\mathrm{km}^{2}$ respectively. Comparing to the flood season at ordinary times the surface runoff is less.

From more than one hundred years ago many environment-friend people in Lanzhou have started to plant trees in the mountain are around Lanzhou. Until now there are artificial urban forest of 580000 
mu and $235000 \mathrm{mu}$ irrigation area. However, the forest coverage rate is still relatively low. Besides, because the city is located in the Yellow River valley, not only the urban heat island (UHI) is more serious than the average level, but also discharging air pollution from the city becomes more complex. In a word, Lanzhou and the vicinity is a region of drought.

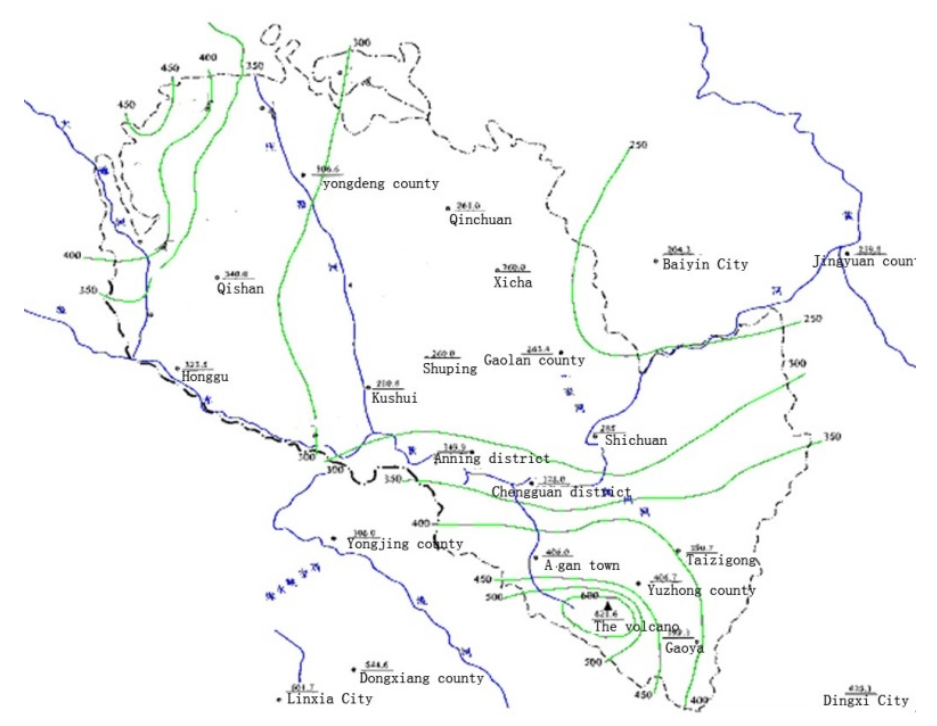

Fig. 1 Average rainfall distribution of Lanzhou in many years

However, the entry of the surface water resources is very rich. The river runoff of the Yellow River, Huangshui, Zhuanglang river, Datong river, Wanchuan river respectively is $330.87 \times 108 \mathrm{~m}^{3} / \mathrm{a}, 16.43 \times$ $108 \mathrm{~m}^{3} / \mathrm{a}, 1.18 \times 108 \mathrm{~m}^{3} / \mathrm{a}, 27.36 \times 108 \mathrm{~m}^{3} / \mathrm{a}, 100 \times 104 \mathrm{~m}^{3} / \mathrm{a}$, as shown in Figure2. It is noted that part of the Yellow River was polluted in the upstream nearby Lanzhou by one of tributary Huangshui flow, which is polluted by nearby large national petrochemical plants. Ironically, it is also where Lanzhou waterworks located, as showed in the Figure 2 and 3.

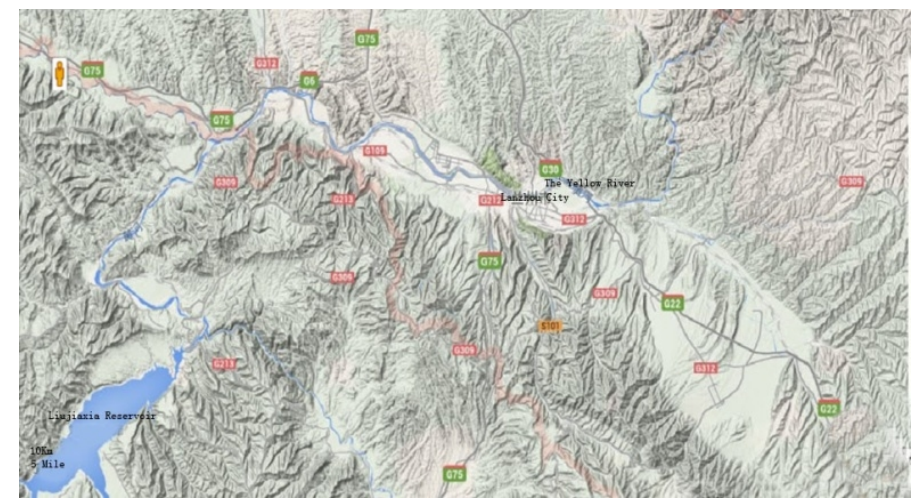

Fig. 2 Liujiaxia reservoir and the Yellow River in Lanzhou

Additionally, it is worth to mention that groundwater is also contaminated by a variety of urban pollutants in Lanzhou. Large amount of untreated water is discharged into the Yellow River. Both water and air pollution poses a great threat to the waterworks of Lanzhou, as showed in the Figure 3. On the one hand, the air pollution in Lanzhou has been improved dramatically, but the threat is still serious. On the other hand, the water pollution problems in the upper reaches of the Yellow River are still unsolved. 


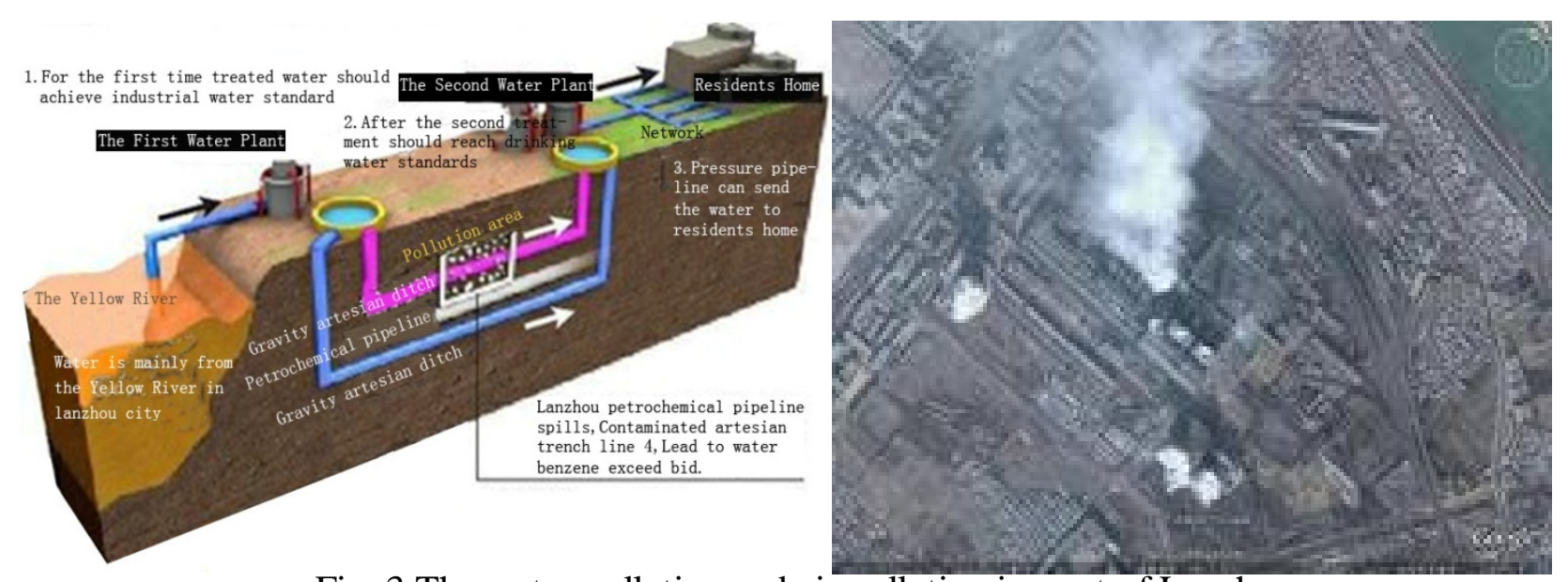

Fig. 3.The water pollution and air pollution in west of Lanzhou

\section{Research on establishment of ecological water system in Lanzhou}

After research we suggest that using ecological solution to the problems that are related to the water pollution in Lanzhou is the best choice.

\section{The new source of city water}

Due to water quality in Liujiaxia reservoir at headwaters of the Yellow River is one level higher than the water quality near Lanzhou. The average altitude of the reservoir storage is $1735 \mathrm{~m}$, while the altitude of Lanzhou is about $1500 \mathrm{~m}$. There is circa $235 \mathrm{~m}$ altitude difference which can be used while transferring water. Obviously, the difference of their gravitational potential energy can save a lot of power and budget. Additionally, the average water resource of Liujiaxia reservoir is about 28.6 billion $\mathrm{m}^{3}$, which accounts for more than $40 \%$ of the one of Yellow River (about 73.5 billion $\mathrm{m}^{3}$ ).

Average annual runoff of the Yellow River is 58 billion $\mathrm{m}^{3}$. Besides, total storage capacity of the Yellow River above Lanzhou is 34 billion $\mathrm{m}^{3}$. The water annual consumption of Lanzhou is about 700 million $\mathrm{m}^{3}$, which is only $2 \%$ of the total amount of the storage.

\section{Two effects of the water conveyance scheme}

In order to construct ecological city water supply system between two mountains as well as in the city Lanzhou, we suggest that water in takes of Lanzhou should be located in the Liujiaxia reservoir, which on is transported to water works as well as the two mountains in Lanzhou. Also, for the geological and budgetary reasons (The line distance between Liujiaxia reservoir and Lanzhou waterworks is about 40 $\mathrm{km}$, as showed in the Figure 4.), we recommend the water transport by pipeline. The straight pipeline transport can save not only a large amount of distance but also gravity drop water saving electricity. And more importantly, according to the principle of gravity drop channel can purify water.

The water transferred to the water works can be further purified and later be piped into the pipe network of city's tap water. The quality of tap water as well as drinking water can be improved greatly. The water transferred to the two mountains can be used to improve ecological environment of the mountains and the city. To be specific, firstly, several large pools named Tianchi will be built on the mountains to store water. Also, a balanced and stable water supply system will at the same time be established, as showed in the Figure 4.Secondly, the ecological water system will be constructed based on the old flood discharge trenches in Lanzhou.(See in the Figure 5) On either side of these ditches there should be as many as possible platforms being established, which can contain water and maximize the amount of green areas. Besides, on these platforms we can establish all kinds of water recycling facilities, such as bend, ponds and artificial wetlands etc. Also, near these ditches straight flood discharge pipes should be built. Obviously there are some problems, such as how to deal with the relationships among the spillway and the bend, ponds and artificial wetlands, how to deal with the whiskering problem in the typical saline-alkali land in Lanzhou, and how to deal with potential landslide problem in platform. 


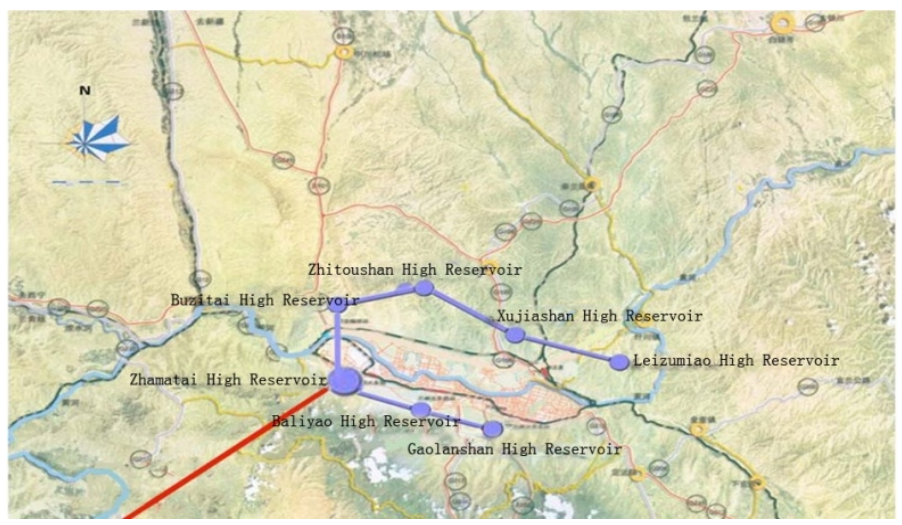

Fig. 4 Schematic diagram of gravity artesian water diversion from the Liujiaxia reservoir

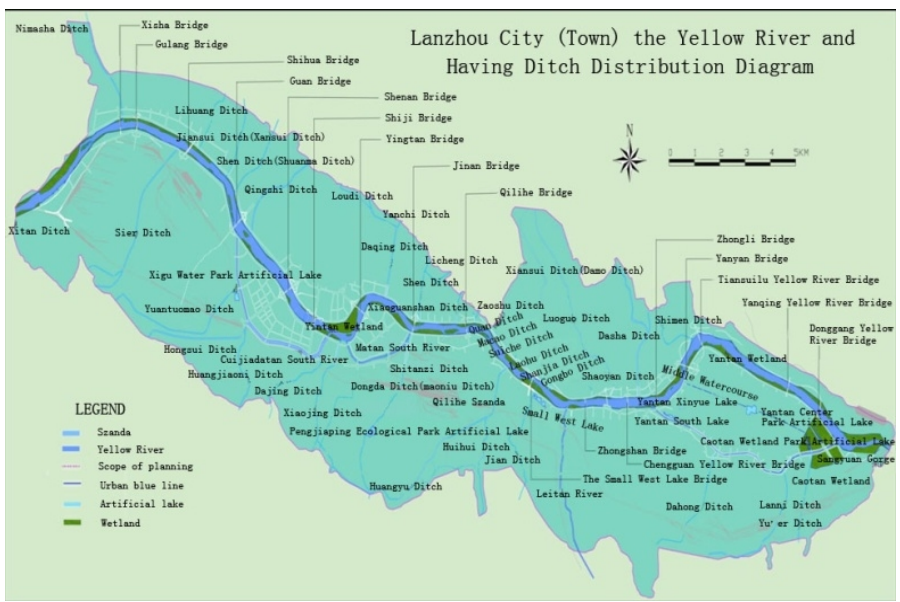

Fig. 5 Old flood discharge trenches and the Yellow River in Lanzhou

Be worth what carry is, due to the high contamination level the Yellow River in the urban areas are not recommended for drinking, landscaping purposes. We suggest on the one hand introducing artificial lakes and bends beside the trenches as many as possible and planting enough selected aquatic plants in those lakes and bends. It is these two ways that purify water.

\section{General status of wetland, wild plants, plant, aquatic plants and wild animals in Lanzhou}

Under the condition of water often $\left(1000 \mathrm{a} 1200 \mathrm{~m}^{3} / \mathrm{s}\right)$ in Lanzhou section of the Yellow River wetland has more than $9700 \mathrm{mu}$, which covers an area of over $100 \mathrm{mu}$ and a total of 65 pieces, a total of 7758 $\mathrm{mu}$. The rest of the narrow wetland has a total of $1942 \mathrm{mu}$. Wetlands are mainly located in the wild goose bay, the central beach, southeast of the beach, Silver Beach Wetland Park, southeast of the wetland park, northeast of Xisha Bridge, toad beach, etc. The rest of the wetlands are on some eyots, and some strip wetlands are located on both sides of the river dispersedly.

Now there are 33 families, 98 genera and 163 species of wild higher plants in the Lanzhou section of the Yellow River wetland, which accounts for respectively the china total number of families, genera and species of $11.32 \%, 3.33 \%$ and $0.67 \%$. Cultivated plants have 31 families, 54 genera and 72 species, most of which were planted in the Silver Beach Wetland Park. Shrub, chamaephyte and aquatic plants were the main types of the cultivated plants.

There are beasts, birds, amphibians, reptiles, fishes, wetland animals in those wetlands. Animals have 2 orders, 4 families, and 8 species, accounting for $4.7 \%$ of the 169 kinds of animals, Gansu province, mainly rat and hare, beast with less resource. Birds is a major type of wetland animals, there are 34 families and 15 orders 1.29, accounting for $26.1 \%$ of the 495 species of birds in Gansu province, the largest Passeriformes birds, followed by Yu shape and en echelon object of birds. There are 9 species of national class II protection. Amphibians have 1 order 2 families 4 species. Reptiles have 2 orders, 4 families and 9 species. The fish have 4 orders, 6 families 26 species. 


\section{Suggestions for the development of ecological city and the two mountains in Lanzhou city}

At present, just rely on the spray irrigation system, the two mountain greening has formed a certain scale. In order to improve the greening effect, we should establish a multi-layer water flow cycle system on the two mountains respectively.

In the urban area, we suggest moving energy-consuming, high pollution, high investment, low value-added project as well as relevant staff and workers from the city valley basin to the new district of Lanzhou in order to improve, transform and even further develop themselves. Furthermore we should build water parks and bended spillways to grow all suitable kinds of aquatic plants, to purify water and to form circulating water systems. A good example of the water park we can find in the wetland park near silver beach bridge.

\section{Suggestions for new district of Lanzhou}

Because the elevation of new district in Lanzhou is (1900 meters to 2300 meters), higher than that of average Lanzhou city, ecological water supply system should be designed with reference of the "Yindaruqin" Water Diversion Project, which has similar circumstance of Lanzhou. But there are different points. Firstly, the land of Lanzhou new district is mostly strong salt and alkaline land. This is also the main cause of the failure of "Yindaruqin" Water Diversion Project. The original purpose of this project is to develop local agriculture. Secondly, there is no green land in the new district of Lanzhou. The current problem is how to deal with whiskering land and planting. Thirdly, how to better construct the new urban ecological water system. Lastly, because of the large distance how to coordinate the ecological water supply system of the new district and the urban? The new district, Lanzhou city and the Yellow River regional relations are showed in the Figure 6.

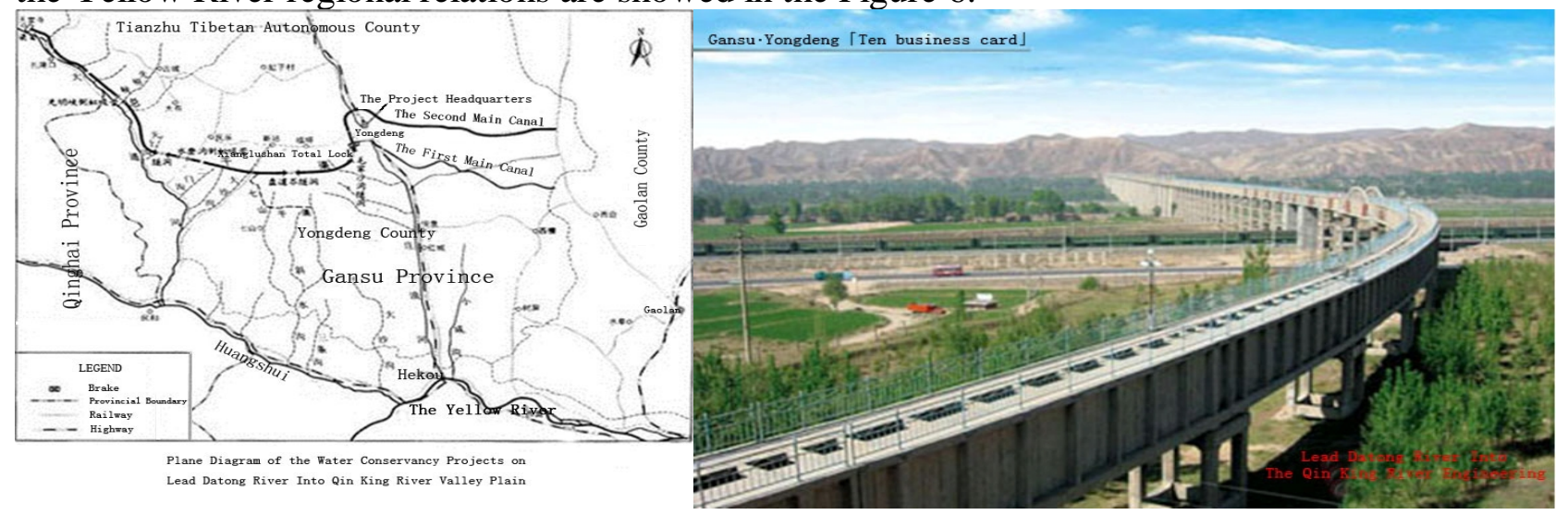

Fig. 6 "Yindaruqin" Water Diversion Project

\section{Implementation and extension of the ecological water system in Lanzhou}

The government will formulate a plan of Lanzhou ecological water supply system. Because the municipal government is using evacuation plan now, many urban land can be built as water parks and spillways. Moreover, the government should also extend the planning to Yongdeng, Gaolan, Yuzhong towns around, even Baiyin City, Dingxi City and other cities in The Lanzhou Urban Economic Circle.

\section{Summary}

By building the independent gravity water diversion project the ecological environment of the23000-mu barren mountains around Lanzhou can be improved dramatically. Besides, the rivers, lakes, flood ditch, wetland, reservoir all around Lanzhou can be connected through ecological water system within the scope of Lanzhou and the surrounding area. Furthermore, the project can save a large amount of water, especially circulating water, which, consequently, cangovern30 new spillways and increase the wetlands about 10 million mu. Ina word, the whole project can promote the virtuous circle of the groundwater, reverse the drawdown (nearly a decade it has fallen about $22 \mathrm{~m}$ ) as well as water quality deterioration, improve the effect of urban heat island and even the local climate, and also restore ecological diversity. After research we firmly believe that this project can help Lanzhou become 
an ecological city, even an outstanding example of ecological reconstruction as well as protection in the whole China.

It is noted that the completed detailed study report about this has been adopted by Lanzhou city government, and has won the provincial social science achievement award certificate. Additionally, the study has also obtained the supports of Gansu Province Urban Development Institute and the Gansu government.

\section{References}

[1] E. Wang, the research report on ecological water system in Lanzhou, Gansu Institute of Urban Development, Lanzhou, 2013

[2] J. Shen, Study on ecological water diversion scheme in high water system of Nantong, Study on ecological water diversion scheme in high water system of Nantong, pp.33-35

[3] F. Niu, C. Wang, W. Chen, Urbanization and Ecological Environment Integrating Dynamic Evaluation in Ecological Economic Region a Case of Yaan, Urban environment \& urban ecology, 17,17-20

[4] Y. Lei, Necessity and Innovative Countermeasures of Water Resource Management in China, Journal of Anhui Agri. Sci, 32 (2007) 10421- 10422

[5] Z. Tang, W. Chen, H. Wu, Analysis of the Water Quality of Han jiangSongyuan River Provincial Boundaries and Environmental Counter measures, Journal of Jiaying University (Natural Science), 26 (2008) 50-54

[6]H. Xiao, Z. Chen, S. Ou, The species diversity of plant community change and its protection in Soil and water loss areas of Changting, Subtropical Soil And Water Conservation, 17(2005) 9-62

[7]Y.He, H. Wu, J. Zhang, The characteristics elements and their planning of the urban ecological water system, Yellow river, 32(2010) 12-13

[8] Y. Liu, Research on Comprehensive Evaluation on Project of Ecological Water to Taohuaxi in Lanzhou, Lanzhou, 2012

[9] C.Liu, Discuss about ecological water system construction mode in Shandong province, Shandong Water Resources, Jinan, 2011, 3-14

[10] X. Chen, H. Ren, X. Yue, Discussion about the build of ecological water system on Baoji section of Weihe River, Shanxi Water Resources, 1 (2011) 